\title{
PANDEMIA E DIREITO CIVIL: INSTRUMENTOS PARA EFETIVAÇÃO DA AUTONOMIA PRIVADA
}

\author{
Cínthia Baccarin ${ }^{1}$ \\ Hiago Andrioti Cordioli ${ }^{2}$ \\ Luciana Lopes Canavez ${ }^{3}$
}

\section{Resumo:}

A questão dos limites da autonomia privada se mostrou pertinente diante das mudanças e incertezas trazidas com a pandemia do novo coronavírus, em especial com a preocupação de garantir a eficácia e salvaguarda da solidariedade e dos direitos à vida e à saúde. O objetivo do estudo foi demonstrar que a autonomia privada ficou amparada em instrumentos preestabelecidos do Direito Civil ao permitirem a manutenção das relações particulares e a contenção de danos em situações imprevisíveis. Utilizamos a análise dedutivo-bibliográfica destes instrumentos, sua relação com os direitos fundamentais e as implicações jurídicas da pandemia, principalmente no tocante à autonomia privada.

Palavras-chave: direito à saúde; autonomia privada; direitos fundamentais; pandemia; COVID-19

\section{PANDEMIC AND CIVIL LAW: INSTRUMENTS FOR EFFECTIVENESS OF PRIVATE AUTONOMY}

\begin{abstract}
:
The issue of the limits of private autonomy proved to matter due the changes and uncertainties brought by the new coronavirus pandemic, in particular the concern to guarantee the effectiveness and safeguard of solidarity and the rights to life and health. The aim of the study was to demonstrate that private autonomy was supported by pre-established instruments of Civil Law by allowing the maintenance of private relations and the containment of damages in unpredictable situations. We used the deductive-bibliographic analysis of these instruments, their relationship with fundamental rights and the legal implications of the pandemic, especially associated with private autonomy.
\end{abstract}

Keywords: right to health; private autonomy; fundamental rights; pandemic; COVID-19

\footnotetext{
${ }^{1}$ Mestranda em Direito pela Universidade Estadual Paulista "Júlio de Mesquita Filho" (UNESP), Faculdade de Ciências Humanas e Sociais (FCHS). E-mail: cinthia.baccarin@unesp.br

2 Mestrando em Direito pela Universidade Estadual Paulista "Júlio de Mesquita Filho" (UNESP), Faculdade de Ciências Humanas e Sociais (FCHS). E-mail: hiago.cordioli@gmail.com

${ }^{3}$ Doutora em Direito pela Faculdade Autônoma de Direito de São Paulo. Mestre em Direito pela Universidade de Franca. Professora titular vinculada ao Departamento de Direito Privado, de Processo Civil e do Trabalho da Universidade Estadual Paulista "Júlio de Mesquita Filho" (UNESP), Faculdade de Ciências Humanas e Sociais (FCHS). E-mail: luciana.canavez@unesp.br.
} 


\section{INTRODUÇÃO}

A Emergência de saúde pública de importância internacional em razão no novo SARS-CoV-2, declarada oficialmente pela Organização Mundial da Saúde em 11 de março de 2020, que ocasionou a pandemia do novo coronavírus, trouxe consigo uma verdadeira revolução da realidade humana, em especial nos âmbitos social, econômico e jurídico. O cotidiano foi substituído por um "novo normal”, com diversas modificações nos hábitos e nas relações humanas, de modo a prevenir a contaminação e combater a doença. A prioridade tornou-se a saúde e a vida das pessoas.

Contudo, não foi tarefa fácil estabelecer limitações à liberdade das pessoas, principalmente no tocante à autonomia privada. De fato, alguns fatores dificultaram um isolamento social concreto e, consequentemente, um enfrentamento da pandemia eficiente, tais como a preocupação com o trabalho e o sustento da família, assim como a falta de diretrizes concretas e unificadas por parte das autoridades competentes, especialmente na esfera federal, a qual causou uma falta de conscientização da população sobre a dimensão da pandemia e de seus efeitos.

Tendo em vista a necessidade de assegurar o bem coletivo e a ordem pública, com base nos direitos à vida e à saúde, as relações privadas restaram comprometidas. Com a insegurança que permeia todos os âmbitos da sociedade, seja na política, na economia e no Direito, antigos instrumentos que asseguravam a manutenção das atividades particulares foram postos à prova.

Com isto, o princípio da autonomia privada encontrou seus limites em uma urgência maior. Ainda assim, mesmo em uma situação de cerceamento das liberdades negociais, instrumentos e institutos já conhecidos do Direito Civil podem permitir a manutenção das relações privadas, ou, pelo menos, diminuir os possíveis danos causados pela impossibilidade do estabelecimento ou continuação de um negócio jurídico.

Neste artigo, faremos uma análise crítica dedutiva (MARCONI; LAKATOS, 2003, p. 91) da pandemia do novo coronavírus e seus efeitos jurídicos e políticos, utilizando o método de procedimento de pesquisa bibliográfica (MARCONI; LAKATOS, 2002, p. 71) com enfoque nas questões relativas ao direito fundamental à saúde e o princípio da autonomia privada, nos atritos e intersecções entre eles, nos instrumentos do Direito Privado aplicáveis para manutenção de relações particulares, como também nas principais dificuldades 
encontradas para um combate eficaz da doença e minimização dos danos tanto na saúde quanto no âmbito privado.

\section{PANDEMIA E DIREITO}

Em dezembro de 2019, um vírus até então desconhecido pela humanidade teve sua eclosão na cidade de Wuhan, na China, e passou a se espalhar rapidamente por todo o mundo. $\mathrm{O}$ vírus foi chamado de SARS-CoV-2 e a doença gerada pela infecção deste novo coronavírus foi denominada de COVID-19.

Apesar da rápida dispersão do vírus para diversos países, a Organização Mundial da Saúde (OMS) só declarou o estado de pandemia em 11 de março de 2020, momento determinante para a tomada de novas estratégias de contenção do vírus. Uma vez que tratavase de uma doença até então desconhecida pela humanidade e, portanto, sem tratamento ou cura conhecidos, os governos dos países, seguindo as orientações da OMS, passaram a recomendar que seus cidadãos se isolassem em suas casas e usassem medidas sanitárias como a higienização das mãos com álcool e o uso de máscaras.

Com o avanço da disseminação do vírus, as recomendações governamentais tornaram-se obrigatórias. No Brasil, os estados e municípios baixaram decretos determinando o fechamento de comércios e serviços considerados não essenciais, proibição de frequentar espaços públicos como praias e shopping centers, imposição de multa para aqueles que não estivessem usando máscaras em locais públicos e comerciais.

Desde o início da pandemia, alertava-se para a questão de que não haveria, no Brasil, uma infraestrutura capaz de suportar os efeitos da doença, caracterizada pela sua rápida disseminação, pelo alto índice de contágio e por provocar sérios problemas respiratórios para uma parcela dos contaminados. Por essa razão, a diretriz principal do Ministério da Saúde foi, a partir da declaração do estado de pandemia pela OMS, que as pessoas ficassem em suas casas e evitassem contatos diretos e próximos com outros.

O Brasil possuía, em abril de 2020, 65 mil respiradores mecânicos, sendo que, destes, 46 mil estavam disponíveis no Sistema Único de Saúde (SUS), tendo adquirido mais 15 mil por causa da pandemia, num investimento de um bilhão de reais (MINISTÉRIO DA SAÚDE, 2020). O número de respiradores por estado é irregular, não atendendo a real proporção para o tamanho populacional. 
Podemos apontar algumas questões e particularidades sobre os direitos fundamentais que foram evidenciados durante esta pandemia do novo coronavírus. Por exemplo, o primeiro direito fundamental elencado na Constituição Federal brasileira de 1988 , em seu art. $5^{\circ}$, o direito à vida ("Todos são iguais perante a lei, sem distinção de qualquer natureza, garantindo-se aos brasileiros e aos estrangeiros residentes no País a inviolabilidade do direito à vida, à liberdade, à igualdade, à segurança e à propriedade [...]”), possui um papel central em todas as discussões envolvendo a pandemia e confronto de direitos.

Outro direito fundamental que, evidentemente, se destaca neste contexto é o direito à saúde, que no ordenamento jurídico brasileiro é tutelado pela Constituição Federal de 1988, principalmente em seu art. $6^{\circ}$ ("São direitos sociais a educação, a saúde, a alimentação, o trabalho, a moradia, o transporte, o lazer, a segurança, a previdência social, a proteção à maternidade e à infância, a assistência aos desamparados, na forma desta Constituição") e no art. 196 (“A saúde é direito de todos e dever do Estado, garantido mediante políticas sociais e econômicas que visem à redução do risco de doença e de outros agravos e ao acesso universal e igualitário às ações e serviços para sua promoção, proteção e recuperação").

A Lei no 8.080/90, a chamada "Lei do SUS", por sua vez, prevê, em seu art. $2^{\circ}$, que "a saúde é um direito fundamental do ser humano, devendo o Estado prover as condições indispensáveis ao seu pleno exercício". Mais ainda, o parágrafo primeiro do mesmo art. dispõe que é dever do Estado garantir a saúde por meio de formulação e execução de políticas econômicas e sociais, visando à redução de riscos de doenças e de outros agravos, bem como no estabelecimento de condições que assegurem acesso universal e igualitário às ações e aos serviços para a sua promoção, proteção e recuperação. O parágrafo segundo complementa, dizendo que "o dever do Estado não exclui o das pessoas, da família, das empresas e da sociedade".

O Sistema Único de Saúde está sempre se provando essencial para o país e para o "sonho" de um direito à saúde universal. Contudo, como temos visto, devemos nos atentar para o problema de que os tratamentos medicamentosos não são o único meio para atingir este direito, sendo a prevenção e a conscientização fundamentais para evitar o colapso da saúde pública.

Uma vez que tratava-se de um vírus e uma doença desconhecidos, para os quais não havia prevenção (vacina), tratamento e muito menos cura, o Estado precisava de outros meios para alcançar a plena efetividade do seu dever de garantir o direito à saúde universal, de modo 
que todos os que fossem contaminados com o vírus e apresentassem sintomas mais graves pudessem ser atendidos e tratados conforme a necessidade. O meio encontrado, então, foi a supressão de direitos relativos à autonomia privada, impedindo que os cidadãos realizassem atividades outrora comuns, como trabalhar, realizar negócios e até mesmo frequentar alguns lugares.

Uma pandemia implica em uma revisão completa de atitudes sociais e governamentais. O governo de um país precisa realocar recursos de diversas áreas para concentrá-las no combate à doença que se alastra e rever políticas, direitos e liberdades tanto no âmbito público quanto no privado, de modo a conter os eventuais danos à sociedade nas suas mais variadas hipóteses.

Em um contexto pandêmico, em que a prioridade é salvaguardar os direitos fundamentais à vida e à saúde, há de se pensar que seria lógico e indiscutível a primazia destes direitos em detrimento de outros. Contudo, como vimos, houve uma certa relativização da "supremacia" dos direitos à vida e à saúde nas políticas e medidas governamentais de enfrentamento da pandemia, assim como pelos próprios cidadãos, invocando, quase sempre, o princípio da autonomia privada.

Nesse sentido, as discussões sobre o sopesamento dos direitos e princípios fundamentais englobam diversos fatores sociais, econômicos e políticos, principalmente em uma situação de vulnerabilidade e incertezas provocadas por uma doença desconhecida. As medidas de isolamento social ameaçaram drasticamente as relações privadas, causando desconforto e indignação por parte da população, que preocupava-se no seu sustento e na continuidade de suas produções e serviços.

Tendo isto em vista, a seguir, faremos uma breve conceituação da autonomia privada, sua aplicação e seus limites em um cenário pandêmico para, por fỉm, discutirmos se houve real cerceamento deste princípio e comprometimento das relações privadas.

\section{AUTONOMIA PRIVADA}

Além dos direitos fundamentais à vida e à saúde, a pandemia teve influência direta na vida econômica e financeira mundial, já que afetou as relações de trabalho, negócios, comércios, fornecimentos, moradia, e assim por diante. 
As relações econômicas e financeira são reguladas, principalmente, por contratos, instrumento que formaliza e faz lei da vontade composta entre os contratantes. A vontade das partes simboliza a expressão de uma das liberdades do indivíduo, o que significa dizer, no âmbito jurídico contratual, que o princípio da autonomia privada está sendo observado. Entretanto, o novo vírus, por ter afetado tantas relações interpessoais e empresariais, acabou abalando e comprometendo a autonomia privada.

Importante, neste momento, explorar o entendimento de autonomia privada e fim de captar sua dimensão e valor, entender sua estreita ligação com os contratos e a segurança jurídica intrínseca, ameaçados pela pandemia.

Compreende-se por autonomia, dentre outras definições, segundo o Dicionário Técnico Jurídico, por "faculdade de alguém reger-se por si mesmo" (GUIMARÃES, 2010, p. 133). Portanto, um indivíduo dotado de autonomia é aquele que autodetermina suas próprias regras, que é independente, que se autogoverna e garante sua vontade. Nesse sentido, autonomia pressupõe dimensões de liberdade de sentimentos, pensamentos, ações e escolhas. Através de uma visão filosófica, não há que se falar em autonomia quando a manifestação de vontade não é plenamente livre. Por tudo isso, pode-se afirmar que a autonomia é uma necessidade humana.

No Direito, a vontade é um objeto de grande consideração, principalmente no âmbito dos direitos pessoais, no qual está situado o contrato. A autonomia proporciona aos indivíduos o reconhecimento pelo Estado do seu status de pessoa. Se o indivíduo tem habilidade para agir, com autonomia e vontade própria, logo lhe é permitido envolver-se em decisões políticas e coletivas, sobretudo em negócios jurídicos.

Embora inquestionável a ilustração da autonomia como expressão da liberdade, evidencia-se o uso desorientado das expressões "autonomia privada" e "autonomia da vontade". Dessa forma, imperioso ressaltar que, em se tratando da relação autonomia e Estado, houveram muitas mudanças nessa percepção de autonomia do indivíduo conforme a modificação dos paradigmas dos modelos estatais.

O modelo de Estado Liberal, que perdurou pelos séculos XVIII e XIX na Europa, tinha estreita relação com o ideal da autonomia da vontade, determinando uma atuação mínima ou quase nula do Estado nas relações particulares, de forma que as partes poderiam dispor de sua plena liberdade nas relações contratuais e obrigacionais. O gradual declínio desse modelo de Estado em muitos países e a crescente preocupação com a garantia da 
igualdade material (tratar os desiguais de forma desigual na medida de sua desigualdade) entre os indivíduos fez surgir a necessidade de atualização do termo, não mais em conformidade com o ilimitado e irrestrito.

Historicamente, de acordo com Bruno Torquato de Oliveira Neves (2007, p. 236), “a autonomia privada é a atualização da autonomia da vontade". Então, o entendimento com relação a autonomia foi modificado após a passagem do paradigma liberal para aquele pautado no bem comum e, hodiernamente, na dignidade da pessoa humana.

Conforme expôs Fernando Noronha (1994, p. 113), “foi precisamente em consequência da revisão a que foram submetidos o liberalismo econômico e, sobretudo, as concepções voluntaristas do negócio jurídico, que se passou a falar em autonomia privada, de preferência à mais antiga autonomia da vontade.”.

O modelo de Estado Social, verificado na Europa no início do século XX, é caracterizado com um viés mais protetivo e intervencionista, cuja preocupação era garantir direitos sociais além da liberdade e da igualdade. Assim, parte da autonomia do indivíduo passou para a preocupação com o "bem comum", ou seja, a autonomia, que antes tinha como fundamento a plena liberdade, teve seu substrato modificado, passando a ser a coletividade.

Com o final da Segunda Guerra Mundial, fundamentado nos princípios da soberania popular e na dignidade da pessoa humana, surgiu, então, o modelo de Estado Democrático de Direito reestruturando os institutos privados e ensejando um aprofundamento teórico acerca do movimento de "constitucionalização do Direito Civil", que perdura até hoje. Atrelado a esse novo paradigma, agora com nova terminologia, a autonomia da vontade passou a ter, portanto, sua liberdade característica limitada conforme a valoração de outros princípios consagrados pela carta constitucional.

[...] trata-se não mais do individualismo do século XVIII, marcado pela supremacia da liberdade individual, mas de um solidarismo inteiramente diverso, em que a autonomia privada e o direito subjetivo são remodelados em função dos objetivos sociais definidos pela Constituição e que, em última análise, voltam-se para o desenvolvimento da personalidade e para a emancipação do homem (TEPEDINO, 2004, p. 560).

As normas civis passam, portanto, a incorporar os ideais e movimentos que permearam todo o século XX e que influenciaram os ordenamentos jurídicos no sentido de atender às demandas sociais que surgiram a partir disso, com irradiação dos princípios 
constitucionais inclusive no âmbito das relações privadas. Gustavo Tepedino, inclusive, trata desta nova abordagem do direito privado sob a luz da Constituição em outra ocasião:

O Código Civil perde, assim, definitivamente, o seu papel de Constituição do direito privado. Os textos constitucionais, paulatinamente, definem princípios relacionados a temas antes reservados exclusivamente ao Código Civil e ao império da vontade: a função social da propriedade, os limites da atividade econômica, a organização da família, matérias típicas do direito privado, passam a integrar uma nova ordem pública constitucional. Por outro lado, o próprio direito civil, através da legislação extracodificada, desloca sua preocupação central, que já não se volta tanto para o indivíduo, senão para as atividades por ele desenvolvidas e os riscos delas decorrentes (TEPEDINO, 2006, p. 41).

Segundo André Rüges e Renata de Lima Rodrigues (2007, p. 15), “a feição que a autonomia privada assume nesse contexto possui contornos de função social, pois consagra o não individual, o bem comum e o bem estar da coletividade sem ignorar a realização dos interesses individuais".

No Brasil, o modelo de Estado Democrático de Direito foi elegido pela Constituição de 1988 e a livre iniciativa e a dignidade da pessoa humana foram consagradas como valores constitucionais de fundamento da República Federativa (art. 1º, III e IV, CF/88). Além disso, existe a preocupação, dentre outras, com a concretização, aplicação e valoração de direitos fundamentais, de forma que a opção escolhida tem estreita relação com a ideia e o termo de autonomia privada.

Ainda no Dicionário Técnico Jurídico, encontra-se a definição de "autonomia da vontade" como sendo o "princípio pelo qual a vontade dos contratantes, ou do agente do ato jurídico, é soberana e produz efeitos legais, quando a pessoa é capaz, não contraria o direito expresso, o interesse coletivo nem a ordem pública.” (GUIMARÃES, 2010, p. 133). Porém, essa definição se encaixa mais adequadamente ao termo autonomia privada, conforme demonstrado antes.

A autonomia privada é, portanto, princípio fundamental do direito privado, aplicado, quase que exclusivamente ao direito das obrigações. Suas fontes são, segundo o Código Civil brasileiro, a lei, como obrigação civil, e os atos unilaterais, o ato ilícito e os contratos, representando obrigações patrimoniais. O contrato é a fonte mais importante e de maior ocorrência nas relações obrigacionais e será especificamente abordado no presente estudo.

Um dos muitos problemas suscitados pelo surto do COVID-19 têm sido seus efeitos nas relações contratuais. A pandemia tem subvertido muitas certezas, vem ameaçando a 
segurança sanitária, econômica, financeira, jurídica, e até existencial e tem testado dia a dia a solidariedade e esperança de todos os seres humanos.

A palavra contrato designa uma forma criada pelo pensamento humano para ordenar o fenômeno econômico, ou seja, da circulação de riqueza de um patrimônio ao outro por meio de atos voluntários, os negócios jurídicos. Negócios esses que vão desde as microtransações em massa sobre bens de consumo, realizadas a todo momento, até as grandes transações econômicas que fazem o mundo girar, como por exemplo, o fornecimento de petróleo a nível mundial, passando por aquilo que é fundamental, os negócios jurídicos destinados a assegurar a vida, sendo eles, os contratos de trabalho e, especificamente no âmbito do direito privado patrimonial, contratos de produção e fornecimento de alimentos, medicamentos, moradia, energia, entre outros.

Existe um vasto universo que cobre desde um nível microeconômico cotidiano até alcançar aqueles contratos a nível da Bolsa de Valores que dão sobressaltos à economia mundial. Ao olhar para esse universo, observa-se, em primeiro lugar, a existência de diversos contratos, como os assimétricos, por adesão, internacionais, paritários, informáticos, normativos, de organização, entre outros. Além disso, todos esses contratos formam conexões na economia mundial, ao passo que todos os contratantes ocupam posições jurídicas de credores e devedores, podendo configurar como parte forte, parte fraca, ou parte igual.

Contratos podem ser considerados, portanto, mecanismos de distribuição dos riscos que podem vir com a passagem do tempo, e também, instrumento pelo qual se consegue tornar o mais seguro possível a incerteza que todo o futuro carrega. Outra função do contrato seria viabilizar a necessária segurança para que os compromissos assumidos sejam observados e realizados no prazo estabelecido. Por isso, os contratos vinculam obrigacionalmente, de modo que seu cumprimento pode ser exigido perante a justiça e, se não cumpridos, geram pretensão à sua execução específica ou à uma indenização pelo inadimplemento.

Contrastando as ideias com o que o novo vírus vem provocando, ou seja, um cenário de incerteza, vulnerabilidade e instabilidade, já que não se sabe quando virá uma vacina, se será eficaz, quando será distribuída a toda população do mundo, quais empresas sobreviverão até esse momento chegar e, até mesmo, qual tipo de consumo se apresentará no mundo pós COVID-19, como tratar os contratos, instituto jurídico funcionalmente regulado pela ideia de segurança, no estado de incerteza causado pela pandemia? Além de não se ter o incentivo e 
confiança na realização de novos contratos, os já existentes também se encontram abalados, seja por impossibilidade total de cumprimento ou seja por parcial, carecendo de reajustes.

O Código Civil brasileiro contém uma disciplina jurídica para as perturbações da relação obrigacional. Todavia, o problema está em que essas soluções, de modo geral, supõem uma instabilidade a qual se seguirá uma normalidade, o que acontece, por exemplo, quando há uma guerra, inflação, terremoto, ou acidente. Existem soluções para o enfrentamento de problemas pontuais de desequilíbrio. Contudo, a instabilidade provocada pela pandemia é de tamanha grandeza e incerteza que não se sabe se haverá o retorno à normalidade.

Frente a essa situação narrada, ocasionada por fatores externos ao contrato, há soluções que podem advir da vontade das partes e há soluções previstas em lei. As primeiras são respostas afirmativas de promoção da autonomia privada, já que as partes vão dispor de sua liberdade de escolha, enquanto que as soluções decorrentes da lei são impostas e, assim, limitadoras da autonomia privada.

Pelo exposto até aqui, os contratos e a segurança jurídica, ao estarem comprometidos, limitam a autonomia privada, já que não existe confiança para a formação de novos vínculos contratuais. Tampouco os indivíduos estão tendo permissão para determinadas ações, especialmente restringidos ao máximo de consagrar novas transações, tudo em razão das restrições decretadas pelas autoridades públicas no combate ao COVID-19. Ademais, as soluções previstas em lei para tentar salvar os contratos já existentes também acabam sendo limitadoras do princípio em questão.

Mais adiante, será verificada a importância do sopesamento entre direitos fundamentais para se chegar a uma conclusão a partir do que vem acontecendo nesse campo jurídico principiológico durante a pandemia. Posteriormente, será disposto acerca dos instrumentos presentes no Código Civil para as situações de extinção, revisão e conservação dos contratos.

\section{DIREITO PRIVADO E PANDEMIA}

A pandemia do novo coronavírus trouxe à baila novamente a controvérsia do embate entre direitos e princípios fundamentais, especificamente, sobre o confronto entre direito à vida e direito à saúde e o princípio da autonomia privada. Em momentos como este, diversos 
instrumentos são invocados como possibilidades de contenção dos efeitos jurídicos que a situação nova desencadeia. Nas palavras de Souza e Silva (2020):

Como sói acontecer diante de um evento fático dessa magnitude, com tantos impactos na vida quotidiana, uma das reações mais imediatas da doutrina costuma ser a de propor possíveis qualificações jurídicas para a crise, de modo a atrair a incidência da normativa que parece ser mais adequada a administrá-la. O empenho subjacente à pluralidade de proposições pode, contudo, ser prejudicial (em vez de benéfico), caso não seja acompanhado do devido respeito aos fundamentos e requisitos próprios de cada instituto. Sem dúvida, o novo coronavírus representa uma novidade fática, porém não inovou na ordem jurídica: as categorias normativas continuam sendo as mesmas de sempre - e, ao menos no campo estrito do direito privado, não parece conveniente a edição de leis de afogadilho, fomentadas pela incerteza e pela ansiedade generalizadas causadas pela pandemia. Cabe ao intérprete, assim, à semelhança do criterioso trabalho desempenhado pelos cientistas de outras áreas, manejar os instrumentos jurídicos com técnica e segurança, sempre com vistas a promover estabilidade (e não a agravar as incertezas ínsitas ao momento).

Nessa seara, faz-se mister lembrar a ideia de equilíbrio entre os direitos e princípios fundamentais. Como nos ensina Robert Alexy (2015), nas colisões entre princípios, um dos princípios tem precedência em face do outro sob determinadas condições. Em outras palavras, nos casos concretos, os princípios têm pesos diferentes, sendo que os princípios com o maior peso têm precedência. Por isso, essas colisões devem ser resolvidas por meio do sopesamento. Ou seja, deve-se considerar as variáveis presentes no caso concreto para atribuir pesos a cada direito e avaliar qual deverá prevalecer, levando em conta o seguinte raciocínio: "Quanto maior for o grau de não satisfação ou de afetação de um princípio, tanto maior terá que ser a importância de satisfação do outro" (ALEXY, 2015, p. 167). Com isso, alcança-se uma relação de precedência condicionada, em que um princípio precede o outro, isto é, sob certas condições, e vice-versa, sob outras.

A partir desse entendimento de sopesamento de direitos e princípios fundamentais, o cenário instalado de combate ao COVID-19, recheado de restrições, pode ser visto como grande limitador da autonomia privada, contudo, não sem relevância alguma, mas em respeito e tolerância à necessidade coletiva de preservação da saúde. Essa restrição acontece na vertente extrapatrimonial ou existencial, melhor dizendo, o indivíduo tem limitação nas decisões dos rumos da própria vida. Por exemplo, quando pacientes diagnosticados ou com suspeitas de contaminação pelo vírus são emergencialmente colocados em isolamento, em quarentena e em tratamento compulsório, conforme prevê o art. $3^{\circ}$, da Lei $n^{\circ}$ 13.979/2020 
(que dispõe sobre as medidas para enfrentamento da emergência de saúde pública de importância internacional decorrente do coronavírus responsável pelo surto de 2019). E essa restrição da autonomia ocorre também em sua faceta patrimonial, ou seja, nos interesses particulares de proprietários e contratantes, diante da quase impossibilidade de movimentação econômica - exceto em se tratando de mercadorias de necessidades básicas -, além da necessidade de adequação dos contratos já existentes.

Entretanto, essas restrições devem encontrar tolerância na medida em que a saúde da coletividade passa a ter uma necessidade de proteção. No caso jurídico brasileiro, o princípio da autonomia privada, seja ela existencial ou patrimonial, encontra limites em outros direitos e princípios constitucionais de grande importância, como qualquer outro no ordenamento jurídico, pois nenhum exercício pode ser absoluto. Nesse quadro pandêmico, o princípio da solidariedade (art. $3^{\circ}, \mathrm{I}, \mathrm{CF} / 88$ ), o direito à vida (art. $5^{\circ}$, caput, $\mathrm{CF} / 88$ ) e o direito à saúde (art. $6^{\circ}$ e 196, CF/88) foram os principais limitadores.

Em tempos de crise como esta já relatada, o princípio da solidariedade e o direito à saúde reconfiguram os limites da liberdade a fim de proteger a dignidade da pessoa humana, o que requer um nível de sacrifício individual.

Com enfoque na autonomia patrimonial, as consequências de um sopesamento entre os direitos e princípios fundamentais impõem aos seus titulares o respeito a interesses socialmente relevantes que na maioria das vezes não coincidem com seus próprios interesses. Notadamente, nas negociações contratuais, a regularização se impõe.

As partes contratantes, portanto, se neste momento estão distantes de um exercício adequado da autonomia privada, precisam encontrar soluções em lei para regulamentar negócios jurídicos prejudicados ou pendentes.

O Código Civil tem um grande "cardápio" que pode ser usado para fazer frente ao fenômeno das perturbações no cumprimento dos contratos causados pelo COVID-19. São previstas algumas possibilidades para as situações de extinção, revisão e conservação dos contratos. A pandemia e sua repercussão sobre as negociações e os contratos remete a categorias clássicas civilistas voltadas para a finalidade de flexibilizar a autonomia privada e a força vinculante dos acordos em face das modificações imprevisíveis. Pode-se pensar em uma diversidade de hipóteses fáticas que provocam o intérprete a buscar no Direito Civil recursos para solução desses casos. 
O Código Civil brasileiro, que regula as relações privadas e os negócios jurídicos, prevê diversas possibilidades em que situações de força maior impedem o cumprimento de uma obrigação ou contrato. No caso do inadimplemento das obrigações, diz o art. 393 que "o devedor não responde pelos prejuízos resultantes de caso fortuito ou força maior, se expressamente não se houver por eles responsabilizado". Seu parágrafo único, inclusive, esclarece que "o caso fortuito ou de força maior verifica-se no fato necessário, cujos efeitos não era possível evitar ou impedir". No contrato de prestação de serviço, conforme o art. 607, uma das hipóteses de término ocorre "pela impossibilidade da continuação do contrato, motivada por força maior". Quanto ao contrato de empreitada, dispõe o art. 625, inciso I, que o empreiteiro poderá suspender a obra por culpa do dono, ou por motivo de força maior.

Diante de uma necessidade de breve conceituação, apresentamos os comentários de Flávio Tartuce a respeito dos institutos de caso fortuito e força maior:

(...) o descumprimento contratual poderá ocorrer por fato alheio à vontade dos contratantes, situação em que estará caracterizada a resolução por inexecução involuntária, ou seja, as hipóteses em que ocorrer a impossibilidade de cumprimento da obrigação em decorrência de caso fortuito (evento totalmente imprevisível) ou de força maior (evento previsível, mas inevitável). (TARTUCE, 2014).

Entendemos, a partir disto, para os efeitos deste trabalho, que a pandemia do novo coronavírus enquadra-se como caso fortuito, por tratar-se de evento imprevisível.

Outra situação prevista no Código Civil é a resolução ou revisão do contrato com base na teoria da imprevisão ou da onerosidade excessiva, com fundamento nos arts. 317, 478, 479 e 480 do diploma. Além da onerosidade excessiva, a exigência é de que o fato novo seja, pelo menos, imprevisível. Isso não se estende aos contratos de consumo, bastando a quebra da base objetiva da proporcionalidade das prestações (art. $6^{\circ}, \mathrm{V}$, da Lei ${ }^{\circ}$ 8.078/1990) (TARTUCE, 2020).

Os arts. 234, 248 e 250, do Código Civil, fundamentam a utilização do instituto da impossibilidade da prestação, mesmo que sem culpa de uma das partes, na resolução ou extinção sem o dever de responder por perdas e danos (TARTUCE, 2020).

Se, por motivo alheio às partes, o contrato perder sua razão de ser, poderá ser considerado extinto, sem perdas e danos, em razão da "frustração do fim da causa do contrato", sendo uma hipótese que encontra argumento pela aplicação do art. 421, do Código 
Civil, (“a liberdade contratual será exercida nos limites da função social do contrato”). (TARTUCE, 2020).

Ainda, a legislação que regula as relações privadas preveem instrumentos e casos de manutenção do contrato, levando em consideração alguns princípios: a boa-fé objetiva, com fundamento nos arts. 113, 187 e 422 do Código Civil; a força obrigatória dos contratos (pacta sunt servanda), surgido a partir da vontade de contratar das partes; a função social do contrato, em sua eficácia interna, de modo a conservar ao máximo os negócios pactuados e a autonomia privada, baseado a partir dos arts. 421 e 2.035, parágrafo único, do Código Civil, o qual pode ser utilizado tanto para a extinção como para a manutenção do contrato; a função social do contrato, em sua eficácia externa, entendendo que a solução contratual não pode trazer lesões a interesses difusos e coletivos, assim como prejuízos a terceiros, como, por exemplo, os consumidores; e, por último, o princípio da intervenção mínima do estado nas relações contratuais, de acordo com o novo parágrafo único do art. 421 do Código Civil, inserido pela citada Lei da Liberdade Econômica (Lei nº13.874/2019) (TARTUCE, 2020).

Os atos e decretos das autoridades de restrição das atividades apenas para o que é essencial, em defesa ao direito à saúde de todos, têm causado nos contratos o desequilíbrio, ora impossibilitando o cumprimento, ora adiando. Assim, muitas vezes as partes não estão conseguindo usar da sua autonomia privada, pois em vez de tentar renegociar o contrato e tentar a autocomposição, elas estão recorrendo às soluções previstas em lei, que não são soluções favoráveis à autonomia, mas são limitadoras, já que são imposições.

Os contratantes são os principais protagonistas nos negócios contratuais, e não seria diferente em cenários de crise diante da necessária reposição do equilíbrio. Assim, podem agir prevendo no contrato cláusulas de adaptação entre a obrigação contratual e a realidade, dispondo de uma margem de liberdade. Em outras palavras, as partes podem renegociar algumas das cláusulas ou estabelecer as causas para extinção do contrato. Não se pode negar que a solução negociada é sempre a melhor escolha, já que promove a autonomia do indivíduo. Sendo assim, é importante o incentivo à autocomposição e, se infrutífera, o Judiciário deverá ser acionado para dar sua resposta. É uma das soluções, portanto, que derivam da autonomia privada.

Contudo, em sua grande maioria, as soluções buscadas para os impactos causados pela pandemia da COVID-19 nas relações contratuais foram perante a lei, de acordo com os 
institutos jurídicos civilistas exemplificados acima, que são, até certo ponto, limitadores da autonomia privada.

Dessa forma, a autonomia privada, sem dúvidas, tem sido mais restringida com esse cenário de adversidade pública para dar maior garantia ao direito fundamental à saúde. Isso vem ocorrendo seja quando os indivíduos são obrigados a ficar confinados em suas residências sem poder garantir, ao menos, o seu sustento (ir trabalhar, produzir, negociar, celebrar novos contratos), ou seja quando a própria situação anterior impede ou adia o cumprimento de uma obrigação contratual sem que busque soluções nos moldes de uma autocomposição.

Podemos apontar a certeza de que os direitos à vida e à saúde são fundamentais pois deles emanam todos os outros. Sendo o Direito criação humana e derivado de sua organização em sociedades, os direitos por nós exercidos são consequências de duas condições básicas: estarmos vivos e em condições de saúde que permitam a expressão da vontade. Sem esses dois direitos fundamentais, não há que se falar em autonomia privada, como no debate em tela.

A autonomia privada sempre sofreu restrições, como vimos, em circunstâncias imprevisíveis ou inevitáveis, especialmente considerando as forças da natureza que não cansam de nos surpreender, apesar do avanço do conhecimento humano e das tecnologias. Estas restrições, porém, somente reafirmam a autonomia e a autodeterminação que os cidadãos possuem para dar continuidade às suas relações particulares.

A restrição de atividades comerciais não essenciais e a restrição da aglomeração de pessoas, a fim de minimizar a proliferação viral, embora sejam medidas de contenção da autonomia privada, são de extrema importância para o momento crítico atual. Inegável que a liberdade individual precisa dar espaço para o bem coletivo. E não poderia ser de outra forma, porque se cada um abrir mão de uma parcela generosa de sua liberdade, ao mesmo tempo estará garantindo, além do direito à saúde de terceiros, também à própria saúde.

\section{CONSIDERAÇÕES FINAIS}

Indubitavelmente, a pandemia do novo coronavírus modificou a vida cotidiana e os negócios jurídicos. Especialmente em um contexto de globalização, em que o mundo está cada vez mais integrado, com conexão direta entre pessoas de vários países, a disseminação 
de uma doença desconhecida e com altos riscos para a saúde, diversos âmbitos da civilização encontram novos desafios.

Neste sentido, nas palavras de Rosenvald e Farias (2017, p. 50), diante de uma "sociedade dinâmica, multifacetada, globalizada e cibernética", as mudanças promovidas pela consequências da atuação do homem não podem passar despercebidas pela Ciência Jurídica; do contrário, haveria uma lacuna entre a realidade e as normas jurídicas. Para isso, o direito precisa estar em harmonia e acompanhar as transformações da sociedade.

Embora a evolução possa nos trazer a ideia de benefícios, como se mostram os progressos na medicina, dentre outros exemplos, o fato é que há uma "crise social e jurídica estampada contemporaneamente" (ZENNI, 2006, p. 13), com relação à personagem mais importante da realidade social: o próprio homem.

Percebe-se que o ser humano está à espreita dos anseios dele mesmo, e isso o torna vítima da ação ilimitada de seu próprio semelhante. A ânsia por poder e lucro a qualquer custo pode fazer com que ele se perca em sua razão e bom-senso, em muito contribuindo para a ocorrência de conflitos no mundo jurídico. De modo geral, o homem almeja ter sua vontade realizada, e nessa busca acaba colidindo com o desejo e direito do outro, provocando um conflito de interesses e direitos que a atual era faz tornar cada vez mais complexo (BAUMAN, 2001, p. 99).

Sob a visão de Boaventura Sousa Santos (2001, p. 23), não faltam promessas da modernidade que não foram cumpridas, ou que simplesmente se renderam a um cumprimento redundantemente perverso. Inúmeras são as condições que causam desconforto e inconformismo, a começar pela desigualdade, a falta de liberdade, o meio ambiente degradado, dentre outras situações causadas pelo homem, das quais ele se torna vítima.

Diante da crise brevemente relatada, o papel do direito como regulamentador e solucionador dos constantes embates experimentados pelos indivíduos ganha destaque em relação ao Estado ou a outro particular. A "missão do direito, por conseguinte, não é outra senão possibilitar que o homem se plenifique na realização de seus fins, no âmago da associação" (ZENNI, 2006, p. 55).

No Direito Civil, a autonomia privada não está sendo exercida em sua forma mais adequada na solução dos desequilíbrios contratuais, tanto em razão do sopesamento de direitos e princípios, pois deve-se dar maior atenção ao direito á vida, à saúde e à 
solidariedade, quanto pelo aumento no uso dos instrumentos civis previstos em lei, que deixam de lado a autocomposição.

O Direito Privado, particularmente, encarou uma série de dificuldades e desafios devido à pandemia. A começar pelo âmbito político, que durante toda a situação emergencial, foi enredado por discussões constantes envolvendo saúde e as relações privadas. A título de exemplo, o Supremo Tribunal Federal assegurou aos estados, municípios e distritos a autonomia para a adoção ou manutenção de medidas restritivas durante a pandemia, como a imposição de distanciamento social, suspensão de atividades de ensino, restrições de comércio, atividades culturais e circulação de pessoas, enquanto o governo federal, por sua vez tentava arduamente acabar com o isolamento e restabelecer a "normalidade". Estes fatos certamente causaram confusão nos agentes privados, que não podiam ter uma segurança jurídica para orientar suas ações no contexto pandêmico.

Em outra perspectiva, os direitos fundamentais aparecem como freios jurídicos inquestionáveis a qualquer tipo de opressão ao homem e à sua dignidade, surgindo como limitação ao Poder do Estado, e, já no cenário contemporâneo, como limitação à autonomia privada. De outra volta, não há como negar o quanto os direitos fundamentais são constantemente violados, tanto por parte do Estado e, principalmente, nas relações entre particulares diante do exacerbado desejo de imposição da autonomia privada, que direta ou indiretamente, prejudica a parte mais fraca da relação, oprimindo direitos fundamentais de terceiros.

Ocorre que, historicamente, no Direito Civil, por muito tempo, não se entendeu haver qualquer limitação à autonomia privada e ao poder de contratar, sendo que, até hoje, tal ideia de restrição ainda encontra salvaguarda. Todavia, atualmente, os direitos fundamentais tendem a ser cada vez mais uma responsabilidade de todos e não só do Estado, devendo ser aplicados e respeitados tanto na relação pública, como nas relações entre particulares. De tal forma, também devem ser assim atendidos tanto pelo poder legislativo, quanto pelo poder judiciário, em sua atuação própria.

Como visto no contexto pandêmico, apesar da garantia da autonomia privada em nosso ordenamento, os negócios jurídicos precisam de soluções para seus entraves. Tendo outros direitos e princípios tomado maior importância, não há autonomia para a realização de novas negociações. As negociações já existentes, por sua vez, precisam de um "rumo". 
A autocomposição seria a forma mais adequada de promover a autonomia privada, respeitando a vontade das partes estabelecida por meio de institutos e cláusulas contratuais prévias. Contudo, na prática, e principalmente em uma situação de incertezas e instabilidade jurídica e política, os contratantes não entram em acordo e precisam recorrer à Lei, na qual vários instrumentos podem ser encontrados, sem que o direito civil precise criar novos mecanismos.

Finalmente, concluímos, diante da situação apresentada, mesmo com as limitações impostas pela necessidade de resguardar os direitos fundamentais à vida e à saúde, a autonomia privada encontrou seu amparo justamente em instrumentos pré-estabelecidos pelo Direito Civil, apenas complementados por adequações e novas interpretações pelos Poderes, de modo a garantir a efetivação e manutenção das relações privadas, diminuindo os danos.

\section{REFERÊNCIAS}

ALEXY, Robert. Teoria dos direitos fundamentais. 2. ed. São Paulo: Malheiros Editores, 2015.

AMARAL NETO, Francisco dos Santos. A autonomia privada como princípio fundamental da ordem jurídica. Perspectivas estrutural e funcional. Revista de Informação Legislativa. Brasília, v. 26, n. 102, p. 207-230, abr./jun. 1989. Disponível em: http://www2.senado.leg.br/bdsf/handle/id/181930. Acesso em: 03 set. 2020.

BAUMAN, Zygmunt. Modernidade Líquida. Tradução Plínio Dentzien. Rio de Janeiro: Jorge Zahar Ed., 2001.

BRASIL. Constituição (1988). Constituição da República Federativa do Brasil, de 05 de outubro de 1988. Brasília: Presidência da República, [2020]. Disponível em:

http://www.planalto.gov.br/ccivil_03/constituicao/constituicao.htm. Acesso em: 06 set. 2020.

BRASIL. Lei n⿳0 8.078, de 11 de setembro de 1990. Dispõe sobre a proteção do consumidor e dá outras providências. Brasília: Presidência da República, 12 set. 1990. Disponível em: http://www.planalto.gov.br/ccivil_03/leis/18078compilado.htm. Acesso em: 21 set. 2020.

BRASIL. Lei $\mathbf{n}^{\mathbf{0}}$ 8.080, de 19 de setembro de 1990. Dispõe sobre as condições para a promoção, proteção e recuperação da saúde, a organização e o funcionamento dos serviços correspondentes e dá outras providências. Brasília: Presidência da República, 20 set. 1990. Disponível em: http://www.planalto.gov.br/ccivil_03/leis/18080.htm. Acesso em: 06 set. 2020.

BRASIL. Lei no 10.406, de 10 de janeiro de 2002. Institui o Código Civil. Brasília: Presidência da República, 11 jan. 2002. Disponível em: http://www.planalto.gov.br/ccivil_03/LEIS/2002/L10406.htm. Acesso em: 07 set. 2020. 
BRASIL. Lei $\mathbf{n}^{0}$ 13.874, de 20 de setembro de 2019. Institui a Declaração de Direitos de Liberdade Econômica [...]. Brasília: Presidência da República, 21 set. 2019. Disponível em: http://www.planalto.gov.br/ccivil_03/_ato2019-2022/2019/lei/L13874.htm. Acesso em: 21 set. 2020.

BRASIL. Lei $\mathbf{n}^{\mathbf{0}}$ 13.979, de 6 de fevereiro de 2020. Dispõe sobre as medidas para enfrentamento da emergência de saúde pública de importância internacional decorrente do coronavírus responsável pelo surto de 2019. Brasília: Presidência da República, 7 fev. 2020. Disponível em: http://www.planalto.gov.br/ccivil_03/_ato2019-2022/2020/lei/113979.htm. Acesso em: 21 set. 2020.

BRASIL. Lei $\mathbf{n}^{0}$ 14.010, de 10 de junho de 2020. Dispõe sobre o Regime Jurídico Emergencial e Transitório das relações jurídicas de Direito Privado (RJET) no período da pandemia do coronavírus (Covid-19). Brasília: Presidência da República, 11 de junho de 2020. Disponível em: http://www.planalto.gov.br/ccivil_03/_Ato2019-

2022/2020/Lei/L14010.htm. Acesso em: 18 set. 2020.

DANTAS BISNETO, Cícero; SANTOS, Romualdo Baptista; CAVET, Caroline Amadori Responsabilidade civil do Estado e pandemia da COVID-19. Revista IBERC, v. 3, n. 2, p. 71-92, 10 jul. 2020. Disponível em:

https://revistaiberc.emnuvens.com.br/iberc/article/view/111/88. Acesso em: 07 set. 2020.

DIREITO à saúde entre a liberdade e a solidariedade: os desafios jurídicos do combate ao novo coronavírus - COVID-19. Migalhas, [s. 1.], 5 mar. 2020. Disponível em:

https://www.migalhas.com.br/coluna/migalhas-de-vulnerabilidade/321211/direito-a-saudeentre-a-liberdade-e-a-solidariedade--os-desafios-juridicos-do-combate-ao-novo-coronavirus--covid-19. Acesso em: 19 set. 2020.

FARIAS, Cristiano Chaves de; ROSENVALD, Nelson. Curso de direito civil: contratos teoria geral e contratos em espécie. v. 4. 5. ed. rev., ampl. e atual. São Paulo: Atlas, 2015.

GAMA, Guilherme Calmon Nogueira da; NEVES, Thiago Ferreira Cardoso. Direito privado emergencial: o regime jurídico transitório nas relações privadas no período da pandemia da COVID-19. Indaiatuba: Foco, 2020.

GORZONI, Paula. Entre o princípio e a regra: teoria dos direitos fundamentais. Novos estudos - CEBRAP, São Paulo, n. 85, p. 273-279, 2009. Disponível em:

http://www.scielo.br/scielo.php?script=sci_arttext\&pid=S0101-

33002009000300013\&lng=pt\&nrm=iso. Acesso em: 10 set. 2020.

GUIMARÃES, Deocleciano Torrieri. Dicionário Técnico Jurídico. 13. ed. São Paulo: Rideel, 2010.

LUDWIG, Guilherme Guimarães. O fato do príncipe e as normas administrativas de suspensão de funcionamento de estabelecimentos na pandemia do COVID-19. In: BELMONTE, Alexandre Agra; MARTINEZ, Luciano; MARANHÃO, Ney. Direito do Trabalho na crise da COVID-19. Salvador: Juspodivm, 2020. p. 471-486. 
MARCONI, Marina de Andrade; LAKATOS, Eva Maria. Fundamentos de metodologia científica. 5. ed. São Paulo: Atlas, 2003.

MARCONI, Marina de Andrade; LAKATOS, Eva Maria. Técnicas de pesquisa. 5. ed. São Paulo: Atlas, 2002.

MATHIAS, Guilherme Valdetaro. Consequências da pandemia criada pela COVID-19 nas obrigações e nos contratos: uma visão pelo ângulo do Direito Civil. Revista da Escola da Magistratura do Estado do Rio de Janeiro. Rio de Janeiro, v. 22, n. 1, p. 284 - 317, jan./mar. 2020.

MINISTÉRIO DA SAÚDE. Saúde adquire 15 mil respiradores. [S. 1.], 04 abr. 2020. Disponível em: https://www.saude.gov.br/noticias/agencia-saude/46657-ministerio-da-saudeadquire-15-mil-respiradores. Acesso em: 06 set. 2020.

MUCELIN, Guilherme. O papel do direito do consumidor para o bem-estar da população brasileira e o enfrentamento à pandemia de COVID-19. Revista de Direito do Consumidor. [S. 1.], v. 129. mai./jun. 2020. Disponível em: https://www.enfam.jus.br/wp-content/uploads/2020/05/Mucelin-Aquino-PandemiaConsumidor-3.1.pdf. Acesso em: 03 set. 2020.

NAVES, Bruno Torquato de Oliveira. Da quebra da autonomia liberal à funcionalização do direito contratual. In: FIUZA, César; NAVES, Bruno Torquato de Oliveira; SÁ, Maria de Fátima Freire (Coord.). Direito Civil: atualidades II. Belo Horizonte: Del Rey, 2007.

NORONHA, Fernando. O direito dos contratos e seus princípios fundamentais: autonomia privada, boa-fé, justiça contratual. São Paulo: Saraiva, 1994.

RÜGER, André; RODRIGUES, Renata de Lima. Autonomia como princípio jurídico estrutural. In: FIUZA, César; NAVES, Bruno Torquato de Oliveira; SÁ, Maria de Fátima Freire (Coord.). Direito Civil: atualidades II. Belo Horizonte: Del Rey, 2007.

ROSENVALD, Nelson. FARIAS, Cristiano Chaves de. Curso de Direito Civil: parte geral e LINDB. 15. ed. rev., ampl. e atual. Salvador: Ed. JusPodivm, 2017.

SANTOS, Boaventura de Sousa. A crítica da razão indolente: contra o desperdício da experiência. 3. ed. vol. 1. São Paulo: Cortez, 2001.

SARLET, Ingo Wolfgang. A eficácia dos direitos fundamentais. 10. ed. rev. atual. e ampl. Porto Alegre: Livraria do Advogado, 2009.

SARLET, Ingo Wolfgang. Dignidade da pessoa humana e direitos fundamentais na Constituição Federal de 1988. 3. ed. Porto Alegre: Livraria do Advogado, 2004.

SARMENTO, Daniel. Direitos Fundamentais e Relações Privadas. Rio de Janeiro: Editora Lúmen Júris, 2008. 
SOUZA, Eduardo Nunes de; SILVA, Rodrigo da Guia. Resolução contratual nos tempos do novo coronavírus. Migalhas. [S. 1.], 25 mar. 2020. Disponível em:

https://www.migalhas.com.br/coluna/migalhas-contratuais/322574/resolucao-contratual-nostempos-do-novo-coronavirus. Acesso em: 18 set. 2020.

TARTUCE, Flávio. Direito Civil: teoria geral dos contratos e contratos em espécie. v. 3. 9 ed. rev., atual. e ampl. São Paulo: Editora Método, 2014.

TARTUCE, Flávio. O coronavírus e os contratos - Extinção, revisão e conservação - Boa-fé, bom senso e solidariedade. Migalhas. [S. 1.], 27 mar. 2020. Disponível em:

https://www.migalhas.com.br/coluna/migalhas-contratuais/322919/o-coronavirus-e-oscontratos-extincao-revisao-e-conservacao-boa-fe-bom-senso-e-solidariedade. Acesso em: 18 set. 2020.

TEPEDINO, Gustavo; OLIVA, Milena Donato; DIAS; Antônio Pedro. Contratos, força maior, excessiva onerosidade e desequilíbrio patrimonial. Conjur, [s. 1.], 20 abr. 2020.

Disponível em: https://www.conjur.com.br/2020-abr-20/opiniao-efeitos-pandemiacovid-19relacoes-patrimoniais. Acesso em: 07 set. 2020.

TEPEDINO, Gustavo. Premissas metodológicas para a constitucionalização do Direito Civil. Revista de Direito do Estado, ano 1, n. 2, p. 37-53. abr./jun. 2006.

TEPEDINO, Gustavo. Temas de Direito Civil. 3. ed. Rio de Janeiro. Renovar, 2004.

UNASUS. Organização Mundial de Saúde declara pandemia do novo Coronavírus. [S. 1.], 11 mar. 2020. Disponível em: https://www.unasus.gov.br/noticia/organizacao-mundial-desaude-declara-pandemia-de-coronavirus. Acesso em: 05 set. 2020.

VENTURA, Deisy. Pandemias e estado de exceção. p. 41-56. Disponível em: http://shorturl.at/uGHQ2. Acesso em: 03 set. 2020.

WHO. Q\&As on COVID-19 and related health topics. [S.1.], 2020. Disponível em: https://www.who.int/emergencies/diseases/novel-coronavirus-2019/question-and-answershub. Acesso em: 03 set. 2020.

ZENNI, Alessandro Severino Vallér. A crise do direito liberal na pós-modernidade. Porto Alegre: Sergio Antonio Fabris Ed., 2006. 